\title{
The nicotinic acetylcholine receptor alpha 4 subunit contains a functionally relevant SNP Haplotype
}

\author{
Marlene Eggert ${ }^{1}$, Georg Winterer ${ }^{2}$, Mario Wanischeck ${ }^{3}$, Jean-Charles Hoda ${ }^{4}$, Daniel Bertrand ${ }^{5}$ and Ortrud Steinlein ${ }^{6 *}$
}

\begin{abstract}
Background: Non-coding single nucleotide polymorphisms within the nicotinic acetylcholine receptor alpha 4 subunit gene (CHRNA4) are robustly associated with various neurological and behavioral phenotypes including schizophrenia, cognition and smoking. The most commonly associated polymorphisms are located in exon 5 and segregate as part of a haplotype. So far it is unknown if this haplotype is indeed functional, or if the observed associations are an indirect effect caused by linkage disequilibrium with not yet identified adjacent functional variants. We therefore analyzed the functional relevance of the exon 5 haplotype alleles.
\end{abstract}

Results: Using voltage clamp experiments we were able to show that the CHRNA4 haplotype alleles differ with respect to their functional effects on receptor sensitivity including reversal of receptor sensitivity between low and high acetylcholine concentrations. The results indicate that underlying mechanisms might include differences in codon usage bias and changes in mRNA stability.

Conclusions: Our data demonstrate that the complementary alleles of the CHRNA4 exon 5 haplotype are functionally relevant, and might therefore be causative for the above mentioned associations.

Keywords: CHRNA4, Acetylcholine receptor, ACh sensitivity, Haplotype, mRNA stability

\section{Background}

Cholinergic effects on cortical information processing and related cognitive performance are partly mediated through stimulation of high-affinity heteromeric $\alpha 4 \beta 2$ nicotinic acetylcholine receptors (nAChRs) [1-4]. $\alpha 4 \beta 2$ receptors are abundantly expressed in human cortex and hippocampus and possess high affinity to (partial) agonists including nicotine and varenicline [5-7]. Receptor upregulation occurs with chronic exposure to agonists and is thought to be regulated on the translational/posttranslational rather than transcriptional level [8-10].

In earlier work, we reported a causative relationship between mutations in exon 5 of CHRNA4 (the nAChR $\alpha 4$-subunit coding gene) and the autosomal dominant nocturnal frontal lobe epilepsy (ADNFLE) - a rare seizure disorder that is frequently associated with neurocognitive deficits or psychiatric affections [11-14]. We then

\footnotetext{
* Correspondence: Ortrud.Steinlein@med.uni-muenchen.de

${ }^{6}$ Ortrud K Steinlein, Institute of Human Genetics,

Ludwig-Maximilians-University Hospital, 80336 Munich, Germany

Full list of author information is available at the end of the article
}

explored in a more recent study, whether association also might exist between human information processing and common CHRNA4 exon 5 single nucleotide polymorphisms (SNPs). Using functional magnetic resonance imaging (fMRI), association, especially for SNP rs1044396, was observed with prefrontal/parietal information processing during a selective attention-requiring task [15]. Complementary behavioral, electrophysiological and neuroimaging studies from other groups have later provided converging evidence supporting the validity of this association. [16-25] Furthermore, we and others repeatedly observed that the common exon 5 SNPs are also associated with endophenotypes of nicotine dependence [26-29].

The CHRNA4 SNPs that repeatedly showed association with neurological and behavioral traits all have in common that they are silent mutations, i.e. are not changing codons and therefore have no apparent effect on the protein sequence. However, during the last decade it has become obvious that not all silent SNPs are functionally neutral. In the present study, we therefore addressed the question if silent CHRNA4 exon 5 SNPs are able to 
modulate mRNA or receptor properties. For this purpose we conducted experiments on receptor sensitivity and mRNA stability, and performed in silico analysis regarding possible codon usage differences introduced by the haplotype alleles.

\section{Results}

\section{Receptor sensitivity analysis}

Exon 5 of the CHRNA4 gene contains a linkage group (haplotype) of synonymous variants (haplotype 5'-rs1044393, rs1044394, rs2229959, rs2229960, rs1044396, rs1044397-3') of hitherto unknown functional relevance. This haplotype rather than single SNPs was chosen for the here reported functional studies because exon 5 SNPs are in linkage disequilibrium with each other. It is therefore not possible to decide if, for example, associations found for a specific SNP are indeed caused by this SNP or by another one located on the same haplotype. Analysis of the haplotype therefore allowed us to simultaneously include all major exon 5 SNPs into our search for functional effects.
Haplotype allele hap1 (T-T-G-T-C-G) corresponds to the NCBI reference sequence (NM000744.5) and has a frequency of $9 \%$ in the general population, while the complementary hap2 allele (C-C-T-C-T-A) accounts for $52 \%$ of all alleles (according to our reference student population). Hap 1 and Hap 2 differ in each single SNP position. Besides hap1 and hap2 at least six other alleles of this haplotype are present in the normal population. These haplotypes share one or more SNP allele with the major haplotypes Hap1 and Hap2 and can therefore be expected to produce intermediate results in functional analysis. They were therefore not included in the present study.

Heterologous expression experiments showed that $\alpha 4 \beta 2$ receptors with both haplotypes yield functional receptors with current amplitudes that increased in a dose-dependent manner with the ACh concentrations (Figure 1). For low ACh doses the currents from hap2 receptors (incl. rs1044396 T-allele) were up to $130 \%$ larger than those from hap1 receptors (incl. rs1044396 C-allele), resulting in a shift of the ha4(hap2) $\beta 2$ curve towards lower concentrations with respect to the curve for ha4(hap1) 32 . For higher doses
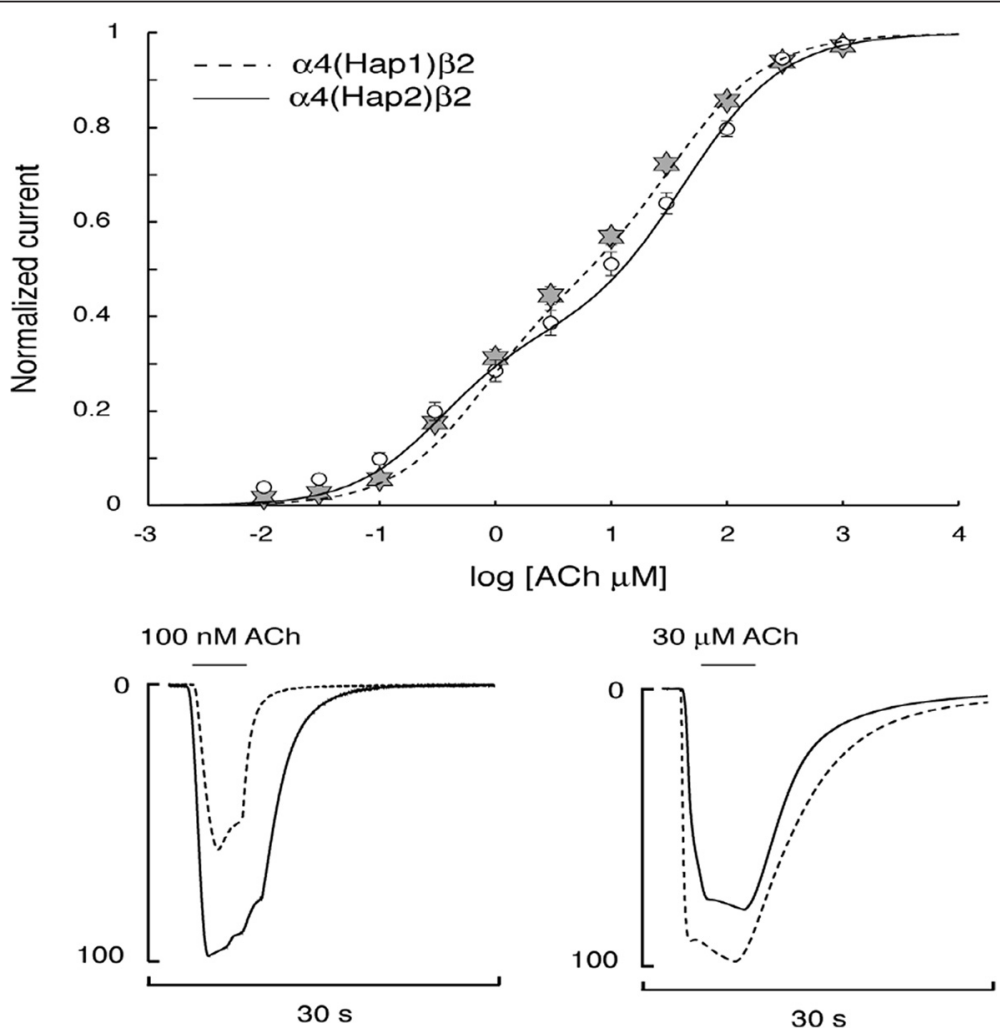

Figure 1 Graphical representation of electrophysiological experiments. a) Concentration activation curves for the a4(hap1) $\beta 2$ and a4(hap2) $\beta 2$ receptors. To minimize scatter, data were collected from large batches of cells. Data obtained from 70 cells expressing the a4(hap1) $\beta 2$ are indicated by stars whereas circles correspond to results collected for 65 cells expressing the $a 4($ hap2) $\beta 2$. Bars indicate the SEM. Continuous curve is the best fit obtained with the sum of two Hill equations for the a4(hap2) $\beta 2$ and dashed line for the a4(hap1)B2. Representative currents evoked by $100 \mathrm{nM}$ and $30 \mu \mathrm{M}$ ACh are illustrated in the lower panel. For comparison responses have been normalized to $100 \%$ for the largest evoked current. These data illustrate the differential, i.e. inverse, sensitivity at the two concentrations between the two haplotype alleles of the a4 $\beta 2$ receptor. 
of ACh the opposite effect was found with currents for h $\alpha 4$ (hap2) $\beta 2$ that were about $13 \%$ lower than those ob-

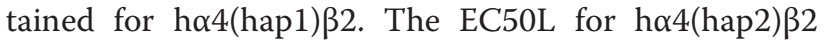
$(0.33 \mu \mathrm{M} \pm 0.017)$ differed significantly $(\mathrm{P} \leq 0.001, \mathrm{n}=65)$ from h $\alpha 4$ (hap1) $\beta 2(0.72 \pm 0.04)$, indicating a higher sensitivity to ACh for ha4(hap2) 32 at low ACh concentrations. Interestingly, the $\mathrm{EC} 50 \mathrm{H}$ data demonstrate a switch in this behavior, pointing to a lower sensitivity to ACh for h $\alpha 4$ (hap2) $\beta 2(42.5 \mu \mathrm{M} \pm 3)$ compared to ho4(hap1) $\beta 2$ (33.6 $\mu \mathrm{M} \pm 2.3, \mathrm{P} \leq 0.05, \mathrm{n}=65)$ in case of high $\mathrm{ACh}$ concentrations (Figure 1).

\section{mRNA stability analysis}

When comparing the mRNA decay time difference of hap 1 and 2, none of the time differences for the four upstream fragments were significant. However, regarding the time difference 0 to $24 \mathrm{hrs}$ for the most downstream fragment, our results revealed that the 3 ' end of hap $1 \mathrm{mRNA}$ was significantly more slowly degraded than that of hap 2 $(\mathrm{P}=0.03)$ (Table 1).

\section{mRNA secondary structure prediction and codon usage analysis}

Analysis of the predicted mRNA secondary structure showed marked differences between the two haplotype alleles (see Additional file 1: Figure S1). Codon usage analysis showed that most SNPs introduced changes from frequently to more rarely used codons or vise versa. These effects were most pronounced for rs2229959, rs1044396 and rs1044397 (see Table 2).

\section{Discussion}

Taken together, our experimental data show that the CHRNA4 haplotype alleles exert different functional effects on mRNA stability as well as on receptor sensitivity including reversal of receptor sensitivity between low and high ACh concentrations. Furthermore, in silico analysis predict that the haplotype alleles also differ with respect to codon usage and mRNA secondary structure. The experiments were conducted using clones that contained identical fragments from the CHRNA4 coding region, the only differences between the clones being the respective alleles of the five SNPs composing the haplotype. Thus the variation observed in both ACh sensitivity and mRNA stability should be attributable to the SNPs within the haplotype. Our results therefore strongly suggest that one or more of the synonymous SNPs that constitute the haplotype are functionally relevant. Such a conclusion would not be too surprising, given that several examples exist in which silent SNPs have been found to modulate gene function, for example by altering mRNA stability, translation efficiency or protein conformation [30-32].
Various mechanisms could explain the distinctive doseresponse curves of the two haplotypes. It is a possibility that the observed changes in mRNA stability are one of the mechanisms that contribute to the haplotypedependent differences in ACh sensitivity. One explanation could be that the altered mRNA stability may lead to an increased translation rate of CHRNA4 mRNA carrying the more stable haplotype 1 . Such an increased translation rate would expand the amount of $\alpha 4$ subunit protein in hap 1 carriers while the amount of $\beta 2$ subunit protein would remain constant. This in turn could alter the nAChRs stoichiometry so that more $(\alpha 4)_{3}(\beta 2)_{2}$ than $(\alpha 4)_{2}(\beta 2)_{3}$ receptor subtypes are assembled. Such changes in stoichiometry are a factor known to influence several functional receptor characteristics and to increase receptor affinity [33,34]. It is also possible that, apart from mRNA stability, additional mechanisms are responsible for the observed differences in agonist sensitivity. For example, changes in the mRNA sequence are known to affect its folding which in turn can influence the efficiency and speed of protein synthesis [35]. This mechanism would also be able to affect the ratio of $\alpha 4$ versus $\beta 2$ subunits within the mature nAChR. Furthermore, codon bias is discussed as mechanism for a gene expression regulation because it has been observed that genes with lower expression levels prefer codons which are recognized by tRNAs with lower gene copy numbers [36].

Another factor that might play a role would be codon bias at the ribosome. It is assumed that the speed at which a given mRNA is decoded at the ribosomes largely depends on the availability of individual tRNA molecules. However, most amino acids can be encoded by more than one base pair triplet, and there are significant differences with respect to the frequency with which individual codons occur in genes. In fact, synonymous codons are used at nonrandom frequencies, a phenomenon termed codon usage bias. Such differences in codon usage are not only found between species, but in some examples also have been described for different tissues from the same individual [37]. Both codon usage and tRNA gene numbers evolved together, and, consequently, tRNAs that recognize frequently used codons are usually more abundant at the ribosome and are therefore more readily available for translation $[37,38]$. Thus a silent SNP changing a frequently used codon into a rarer one can slow down the speed of mRNA translation. In fact, synonymous codon usage is recognized as the primary cause of non-uniform translation rates, a mechanism known to cause for differential maturation and folding of nascent polypeptides [39]. These differences in polypeptide processing are possible because the time newly synthesized polypeptides spend at the ribosome is used to introduce various modifications that are important for protein folding, stability, and interaction with binding partners [40]. The 
Table 1 Delta $C_{q}$ mean values and $p$-values for qPCR fragments 1 to 5

\begin{tabular}{|c|c|c|c|c|c|c|c|c|c|c|c|c|c|c|c|}
\hline \multirow{4}{*}{$\begin{array}{l}\text { mRNA decay } \\
\text { time difference }\end{array}$} & \multicolumn{15}{|c|}{ qPCR fragment } \\
\hline & \multicolumn{3}{|l|}{1} & \multicolumn{3}{|l|}{2} & \multicolumn{3}{|l|}{3} & \multicolumn{3}{|l|}{4} & \multicolumn{3}{|l|}{5} \\
\hline & \multicolumn{2}{|l|}{$\Delta C_{q}$ mean } & \multirow{2}{*}{$\begin{array}{l}p \text {-value } \\
\text { hap } 1 / 2\end{array}$} & \multicolumn{2}{|l|}{$\Delta C_{q}$ mean } & \multirow{2}{*}{$\begin{array}{l}\text { p-value } \\
\text { hap } 1 / 2\end{array}$} & \multicolumn{2}{|l|}{$\Delta C_{q}$ mean } & \multirow{2}{*}{$\begin{array}{l}\text { p-value } \\
\text { hap1/2 }\end{array}$} & \multicolumn{2}{|l|}{$\Delta C_{q}$ mean } & \multirow{2}{*}{$\begin{array}{l}\mathrm{p} \text {-value } \\
\text { hap } 1 / 2\end{array}$} & \multicolumn{2}{|l|}{$\Delta C_{q}$ mean } & \multirow{2}{*}{$\begin{array}{l}\text { p-value } \\
\text { hap1/2 }\end{array}$} \\
\hline & hap 1 & hap 2 & & hap 1 & hap 2 & & hap 1 & hap 2 & & hap 1 & hap 2 & & hap 1 & hap 2 & \\
\hline \multirow[t]{2}{*}{0 to $3 \mathrm{hrs}$} & 1.16 & 0.29 & 0.242 & 1.91 & 0.09 & $0.029^{1}$ & 1.61 & 0.26 & 0.066 & 1.07 & -0.07 & 0.08 & 1.17 & 0.37 & 0.436 \\
\hline & $(-0.72-3.04)$ & $(-1.57-2.15)$ & & $(-0.31-4.12)$ & $(-1.77-1.94)$ & & $(-0.73-3.95)$ & $(-1.61-2.13)$ & & $(-0.70-2.83)$ & $(-1.66-1.51)$ & & $(-1.48-3.81)$ & $(-1.73-2.47)$ & \\
\hline \multirow[t]{2}{*}{0 to $6 \mathrm{hrs}$} & 2.54 & 1.95 & 0.403 & 3.34 & 2.41 & 0.313 & 3.04 & 2.48 & 0.546 & 2.23 & 1.7 & 0.503 & 3.69 & 3.34 & 0.821 \\
\hline & $(0.49-4.58)$ & $(0.63-3.27)$ & & $(0.79-5.89)$ & $(0.77-4.04)$ & & $(0.43-5.65)$ & $(0.75-4.21)$ & & $(0.26-4.19)$ & $(0.29-3.11)$ & & $(0.72-6.66)$ & $(0.71-5.97)$ & \\
\hline \multirow[t]{2}{*}{0 to $24 \mathrm{hrs}$} & 5.74 & 5.64 & 0.918 & 6.18 & 6.24 & 0.952 & 5.06 & 4.77 & 0.778 & 5.21 & 4.77 & 0.679 & 8.16 & 10.73 & $0.036^{2}$ \\
\hline & (3.86-7.62) & $(3.22-8.06)$ & & $(4.02-8.33)$ & (3.84-8.63) & & $(2.79-7.34)$ & $(2.55-7.00)$ & & $(3.55-6.87)$ & $(2.23-7.32)$ & & $(5.42-10.90)$ & (6.03-13.44) & \\
\hline
\end{tabular}

$\Delta C_{q}$ mean, delta $C_{q}$ mean: difference of the mean quantification cycle; confidence intervals are given in brackets.

${ }^{1}$ confidence interval for delta $C_{\mathrm{q}}$-mean values of hap1 and hap2 are not significant.

${ }^{2}$ confidence interval for delta $C_{\mathrm{q}}$-mean values of hap1 and hap2 are significant. 
Table 2 Changes of codon usage frequencies within the haplotype

\begin{tabular}{llll}
\hline dbSNP ID & $\begin{array}{l}\text { amino acid } \\
\text { positions }\end{array}$ & $\begin{array}{l}\text { Alleles (hap } \\
\text { 1/hap 2) }\end{array}$ & $\begin{array}{l}\text { Codon usage frequencies } \\
\text { (hap 1/hap 2) }\end{array}$ \\
\hline rs1044393 & D213 & GAT/GAC & $21,8 / 25,1$ \\
rs1044394 & C226 & TGT/TGC & $10,6 / 12,6$ \\
rs2229959 & P403 & CCG/CCT & $6,9 / 17,5$ \\
rs2229960 & C409 & TGT/TGC & $10,6 / 12,6$ \\
rs1044396 & S543 & AGC/AGT & $19,5 / 12,1$ \\
rs1044397 & A553 & G/A & $7,4 / 15,8$ \\
\hline
\end{tabular}

Data source for codon usage: http://www.kazusa.or.jp/codon/.

silent SNPs that constitute the CHRNA4 haplotype introduce several changes from frequent to rarer used codons (or vise versa, see Table 2) and could therefore alter, by the above discussed mechanisms, functional characteristics of the nAChR such as stoichiometry, surface expression or function. Pathomechanisms like this have already been reported for other silent SNPs associated with human disorders [31,35,41].

It appears remarkable that, within our experimental setting, mRNA stability was only altered in the downstream (3') region of the cloned CHRNA4 coding region fragment. These observations suggest that it is the SNPs in the 3' part of the haplotype that are able to alter mRNA stability. Interestingly, the 3' end of the CHRNA4 haplotype harbors the two silent SNPs that have most consistently shown association with clinical phenotypes. For example, recent work from several groups including our own reported association between rs1044396/ rs1044397 and endophenotypes of schizophrenia as well as nicotine addiction. Both SNPs are significantly associated with cognitive endophenotypes such as brain activation (N100-amplitude - in particular in prefrontal cortex) during selective-attention-requiring tasks [15-19,21,23-26]. With a minor allele frequency above 0.45 both SNPs would be common enough to contribute considerably to the inter-individual variability in the processing of cognitive tasks, addictive behavior and psychiatric disorders within the general population. Additional studies are needed to shed light on the complex interactions between these silent $\mathrm{nAChR}$ variants, differences in $\mathrm{nAChR}$ function, and the inter-individual variability of neurological and behavioral traits in humans.

\section{Conclusions}

Our experimental and in silico data demonstrate that the complementary alleles of the CHRNA4 exon 5 haplotype differ with respect to mRNA stability, codon usage, and agonist sensitivity. These results render it possible that one or more of the haplotype-constituting SNPs are causative for the previously reported associations with neurological and behavioral phenotypes.

\section{Materials and Methods}

\section{Receptor sensitivity analysis}

The cDNAs with either one of the two complementary CHRNA4 haplotypes and with the CHRNB2 wild type sequence were injected in Xenopus oocytes in equal amounts and the electrophysiological properties of the $\alpha 4 \beta 2$ nAChR channel were determined using a twoelectrode voltage clamp technique (HiClamp, Multichannel System $^{\circ}$, Reutlingen Germany) and applying different concentrations of acetylcholine (ACh). Concentrationactivation curves were fitted using a Hill equation in the form $\mathrm{Y}=1 / 1+(\mathrm{EC} 50 / \mathrm{x})^{\wedge} \mathrm{nH}(1)$ where: $\mathrm{y}=$ the fraction of evoked current, EC50 = concentration for 50\% activation of the high affinity, $\mathrm{nH}=$ the apparent cooperativity for the high affinity, $\mathrm{x}=$ agonist concentration. Concentration-inhibition curves are fit with a comparable equation $\mathrm{Y}=1 / 1+(\mathrm{x} / \mathrm{IC} 50)^{\wedge} \mathrm{nH}(2)$ where: $\mathrm{y}=$ the fraction of remaining current, IC50 $=$ concentration for $50 \%$ inhibition, $\mathrm{nH}=$ the apparent cooperativity, $\mathrm{x}=$ antagonist concentration.

\section{mRNA stability testing}

The Tet-Off ${ }^{\oplus}$ advanced inducible gene expression system was purchased from Clontech (Saint-Germain-en-Laye, France). The coding sequence of CHRNA4 hap 1, respectively hap 2 was obtained by PCR amplification of human

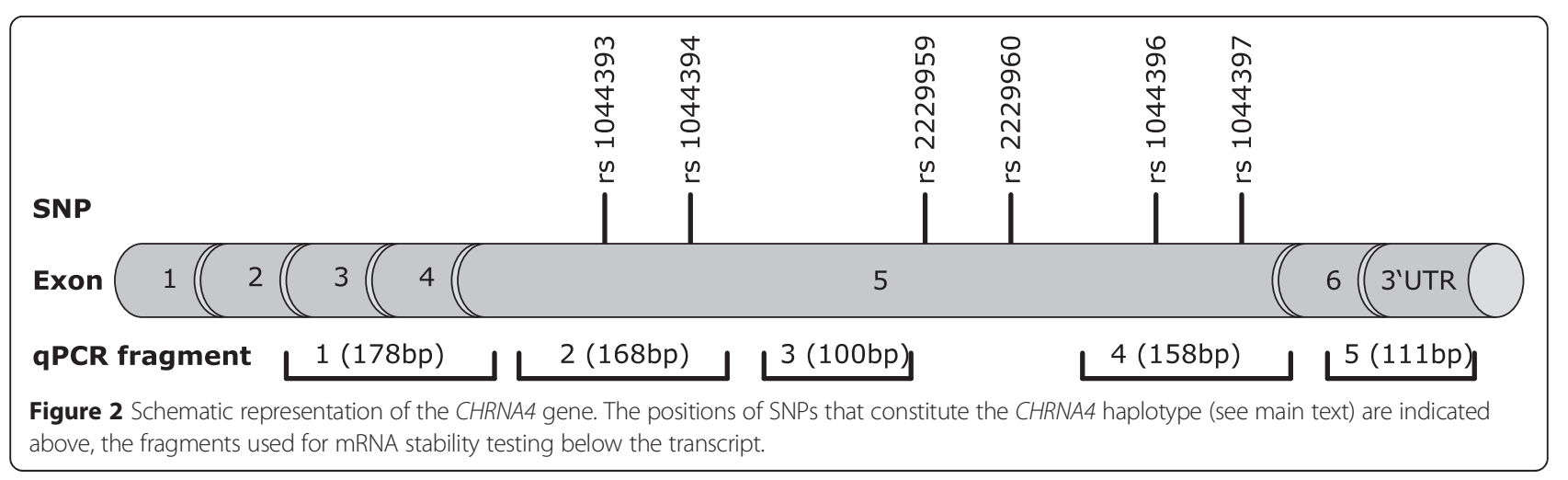


DNA. After KpnI and EcorV digestion of the pTRE-TightBI-AcGFP1 vector, the coding sequence of CHRNA4 hap 1 , respectively hap 2 (1884 $\mathrm{nt}$ ) was ligated into the multiple cloning site of pTRE-Tight-BI-AcGFP1 downstream of the doxycycline-dependent promoter. The resulting construct had the following structure (origin of fragments given in brackets): (pTRE-Tight) ...GCTCGGTAC (pTRACER) CGAGCTCGGATCCA (CHRNA4 uncoding) CTAGTAGTGCGCC (CHRNA4 coding) ATG...TAG (CHRNA4 uncoding) GAATAG (pTRACER) GAATTC TGCAGAT (pTRE-Tight) ATCTC... After cloning the inserts were confirmed by sequencing. Culturing of Tet-Off ${ }^{\circ}$ human embryonic kidney cells (HEK) 293 (Clontech, Saint-Germain-en-Laye, France) was performed using standard protocols. HEK 293 cells were transfected with $10 \mathrm{ng}$ plasmid pTRE-Tight-BI-AcGFP1 containing the coding sequence of CHRNA4 haplotype 1 and 2, respectively, using $3 \mu \mathrm{l}$ of TransIT ${ }^{\circ}$-LT1 Transfection Reagent (MoBiTec GmbH, Göttingen, Germany) with $24 \mathrm{~h}$ transfection prior to medium change and addition of $1 \mu \mathrm{g}$ doxycycline. RNA was extracted after $0 ; 3 ; 6$ and 24 hours of doxycycline incubation by using QIAshredder and RNeasy kit, including DNase treatment of $10 \mathrm{~min}$ in solution, according to the manufacturer's protocol (Qiagen, Hilden, Germany). Real-time PCR was performed targeting five fragments of the CHRNA4 coding sequence (primer sequences: $1 \mathrm{~F}$ GCTCATTGACGTGGATGAGA, 1R CCCGTCAGCATTGTTGTAGA, 2 F GCTGGACTT CTGGGAGAGTG, 2R AGgGGATGATGAGGTTGATG, 3 F TGCTCATCACCGAGATCATC, 3R ATGACGATG GACAGGGTGAC, 5 F AAGGAGCCCTCTTCGGTGTC, 5R CTTCGGCCTTCAGGTGGTCT, 5 F GGCTGGCAT GATCTAGGAAT, 5R GGGAGGTGTGGGAGGTTTTT, AcGFP_F ATGATGTATCGCCCTCGAAC, AcGFP R CA CATGAAGCAGCACGACTT) (Figure 2). Amplification efficiency and test linearity (correlation coefficient R2) were assessed for each primer pair. The reactions were carried out in the Mini Opticon CFD-3120 cycler (Bio-Rad, Munich, Germany). All experiments were repeated independently three times with triplicate biological and triplicate technical samples (nine experiments each in total). Statistical analysis was performed with program $\mathrm{R}$ to compare the haplotype 1 and 2 RNA degradation rate for each target fragment. A $p$ value of $p<0.05$ was considered statistically significant.

Prediction of mRNA secondary structure and codon usage Changes in the minimum free energy (MFE) secondary structure caused by the haplotype alleles were predicted by the use of the RNA fold web server, Vienna RNA package (http://rna.tbi.univie.ac.at/cgi-bin/RNAfold.cgi). A prediction software was employed for the codon usage analysis (http://www.kazusa.or.jp/codon).

\section{Additional file}

Additional file 1: Figure S1. Minimum free energy structure of CHRNA4 haplotype mRNAs. The minimum free energy secondary structures for both CHRNA4 haplotypes were calculated from base-pairing probabilities, using the share ware program RNAfold web server (http://rna.tbi.univie.ac.at/cgibin/RNAfold.cgi). The prediction shows the optimal secondary structure [42].

\section{Abbreviations}

ACh: Acetylcholine; ADNFLE: Autosomal dominant nocturnal frontal lobe epilepsy; CHRNA4: Nicotinic acetylcholine receptor alpha 4 subunit gene; CHRNB2: Nicotinic acetylcholine receptor beta 2 subunit gene; fMRl: Functional magnetic resonance imaging; nAChRs: Nicotinic acetylcholine receptors; SNPs: Single nucleotide polymorphisms.

\section{Competing interests}

The authors declare that they have no financial or non-financial competing interests.

\section{Author contributions}

OST and DB planned the study and analyzed the data. JCH conducted the electrophysiological experiments. ME and MW performed the molecular genetic experiments. OST, DB and GW wrote the manuscript. All authors read and approved the final manuscript.

\section{Acknowledgements}

The study was funded by the Deutsche Forschungsgemeinschaft (DFG SPP 1226, STE 1651/1-3 and BE 3834/1-2).

\section{Author details}

${ }^{1}$ Marlene Eggert, Institute of Human Genetics, Ludwig-Maximilians-University Hospital, 80336 Munich, Germany. ${ }^{2}$ Georg Winterer, Experimental and Clinical Research Center (ECRC), Charité - University Medicine Berlin, Berlin, Germany. ${ }^{3}$ Mario Wanischeck, Institute of Human Genetics,

Ludwig-Maximilians-University Hospital, 80336 Munich, Germany.

${ }^{4}$ Jean-Charles Hoda, SwissCheckUp SA, 1400 Yverdon-Les-Bains, Switzerland.

${ }^{5}$ Daniel Bertrand, HiQScreen, 1222 Vésenaz, Geneva, Switzerland. ${ }^{6}$ Ortrud K

Steinlein, Institute of Human Genetics, Ludwig-Maximilians-University

Hospital, 80336 Munich, Germany.

Received: 18 December 2014 Accepted: 22 April 2015

Published online: 02 May 2015

\section{References}

1. Grottick AJ, Higgins GA. Effect of subtype selective nicotinic compounds on attention as assessed by the five-choice serial reaction time task. Behav Brain Res. 2000;117(1-2):197-208.

2. Grottick AJ, Wyler R, Higgins GA. A study of the nicotinic agonist SIB-1553A on locomotion, and attention as measured by the five-choice serial reaction time task. Pharmacol Biochem Be. 2001;70(4):505-13.

3. Levin ED, McClernon FJ, Rezvani AH. Nicotinic effects on cognitive function: behavioral characterization, pharmacological specification, and anatomic localization. Psychopharmacology. 2006;184(3-4):523-39.

4. Wildeboer KM, Stevens KE. Stimulation of the alpha 4 beta 2 nicotinic receptor by $5-1$ A-85380 improves auditory gating in DBA/2 mice. Brain Res. 2008;1224:29-36.

5. Hellstrom-Lindahl E, Mousavi M, Zhang X, Ravid R, Nordberg A. Regional distribution of nicotinic receptor subunit mRNAs in human brain: comparison between Alzheimer and normal brain. Mol Brain Res. 1999;66(1-2):94-103.

6. Burghaus L, Schutz U, Krempel U, de Vos RAl, Steur ENHJ, Wevers A, et al. Quantitative assessment of nicotinic acetylcholine receptor proteins in the cerebral cortex of Alzheimer patients. Mol Brain Res. 2000;76(2):385-8.

7. Rucktooa P, Haseler CA, van Elk R, Smit AB, Gallagher T, Sixma TK. Structural characterization of binding mode of smoking cessation drugs to Nicotinic Acetylcholine receptors through study of Ligand complexes with Acetylcholine-binding protein. J Biol Chem. 2012;287(28):23283-93.

8. Teaktong T, Graham AJ, Johnson M, Court JA, Perry EK. Selective changes in nicotinic acetylcholine receptor subtypes related to tobacco smoking: an immunohistochemical study. Neuropath Appl Neuro. 2004;30(3):243-54. 
9. Wevers A, Burghaus L, Moser N, Witter B, Steinlein OK, Schutz U, et al. Expression of nicotinic acetylcholine receptors in Alzheimer's disease: postmortem investigations and experimental approaches. Behav Brain Res. 2000;113(1-2):207-15.

10. Mobascher A, Winterer $\mathrm{G}$. The molecular and cellular neurobiology of nicotine abuse in schizophrenia. Pharmacopsychiatry. 2008;41:S51-9.

11. Steinlein OK, Mulley JC, Propping P, Wallace RH, Phillips HA, Sutherland GR, et al. A Missense mutation in the neuronal nicotinic Acetylcholine-receptor alpha-4 subunit is associated with Autosomal-dominant nocturnal frontallobe Epilepsy. Nat Genet. 1995;11(2):201-3.

12. Magnusson A, Stordal E, Brodtkorb E, Steinlein O. Schizophrenia, psychotic illness and other psychiatric symptoms in families with autosomal dominant nocturnal frontal lobe epilepsy caused by different mutations. Psychiat Genet. 2003;13(2):91-5.

13. Bertrand D, Elmslie F, Hughes E, Trounce J, Sander T, Bertrand S, et al. The CHRNB2 mutation 1312M is associated with epilepsy and distinct memory deficits. Neurobiol Dis. 2005;20(3):799-804.

14. Bertrand S, Weiland S, Berkovic SF, Steinlein OK, Bertrand D. Properties of neuronal nicotinic acetylcholine receptor mutants from humans suffering from autosomal dominant nocturnal frontal lobe epilepsy. Brit J Pharmacol. 1998;125(4):751-60.

15. Winterer G, Musso F, Konrad A, Vucurevic G, Stoeter P, Sander T, et al. Association of attentional network function with exon 5 variations of the CHRNA4 gene. Hum Mol Genet. 2007;16(18):2165-74.

16. Parasuraman R, Greenwood PM, Kumar R, Fossella J. Beyond heritability Neurotransmitter genes differentially modulate visuospatial attention and working memory. Psychol Sci. 2005;16(3):200-7.

17. Espeseth T, Endestad T, Rootwelt $H$, Reinvang I. Nicotine receptor gene CHRNA4 modulates early event-related potentials in auditory and visual oddball target detection tasks. Neuroscience. 2007;147(4):974-85.

18. Greenwood PM, Fossella JA, Parasuraman R. Specificity of the effect of a nicotinic receptor polymorphism on individual differences in visuospatial attention. J Cognitive Neurosci. 2005;17(10):1611-20.

19. Greenwood PM, Lin MK, Sundararajan R, Fryxell KJ, Parasuraman R. Synergistic effects of genetic variation in nicotinic and muscarinic receptors on visual attention but not working memory. Proc Natl Acad Sci U S A. 2009;106(9):3633-8.

20. Greenwood PM, Sundararajan R, Lin MK, Kumar R, Fryxell KJ, Parasuraman R. Both a Nicotinic single Nucleotide Polymorphism (SNP) and a noradrenergic snp modulate working memory performance when attention is manipulated. J Cognitive Neurosci. 2009;21(11):2139-53.

21. Reinvang I, Lundervold AJ, Rootwelt $H$, Wehling E, Espeseth T. Individual variation in a cholinergic receptor gene modulates attention. Neurosci Lett. 2009;453(3):131-4.

22. Markett SA, Montag C, Reuter M. The association between dopamine DRD2 polymorphisms and working memory capacity is modulated by a functional Polymorphism on the nicotinic receptor gene CHRNA4. J Cognitive Neurosci. 2010;22(9):1944-54.

23. Markett S, Montag C, Walter NT, Reuter M. Evidence for the modality independence of the genetic epistasis between the dopaminergic and cholinergic system on working memory capacity. Eur Neuropsychopharm. 2011;21(2):216-20.

24. Markett S, Reuter M, Montag C, Weber B. The dopamine D2 receptor gene DRD2 and the nicotinic acetylcholine receptor gene CHRNA4 interact on striatal gray matter volume: evidence from a genetic imaging study. Neuroimage. 2013;64:167-72.

25. Giessing C, Neber T, Thiel CM. Genetic variation in nicotinic receptors affects brain networks involved in reorienting attention. Neuroimage. 2012:59(1):831-9.

26. Feng $Y$, Niu TH, Xing HX, Xu X, Chen CZ, Peng SJ, et al. A common haplotype of the nicotine acetylcholine receptor alpha 4 subunit gene is associated with vulnerability to nicotine addiction in men. Am J Hum Genet. 2004;75(1):112-21.

27. Li MD, Beuten J, Ma JZ, Payne TJ, Lou XY, Garcia V, et al. Ethnic- and genderspecific association of the nicotinic acetylcholine receptor alpha 4 subunit gene (CHRNA4) with nicotine dependence. Hum Mol Genet. 2005;14(9):1211-9.

28. Breitling LP, Dahmen N, Mittelstrass K, Rujescu D, Gallinat J, Fehr C, et al. Association of nicotinic acetylcholine receptor subunit alpha 4 polymorphisms with nicotine dependence in 5500 Germans. Pharmacogenomics J. 2009:9(4):219-24.

29. Kamens HM, Corley RP, McQueen MB, Stallings MC, Hopfer CJ, Crowley TJ, et al. Nominal association with CHRNA4 variants and nicotine dependence. Genes Brain Behav. 2013;12(3):297-304.
30. Nackley AG, Shabalina SA, Tchivileva IE, Satterfield K, Korchynskyi O, Makarov SS, et al. Human catechol-O-methyltransferase haplotypes modulate protein expression by altering mRNA secondary structure. Science. 2006;314(5807):1930-3.

31. Kimchi-Sarfaty C. A 'silent' polymorphism in the MDR1 gene changes substrate specificity (vol 315, pg 525, 2007). Science. 2007;318(5855):1382-3.

32. Tsai CJ, Sauna ZE, Kimchi-Sarfaty C, Ambudkar SV, Gottesman MM, Nussinov R. Synonymous mutations and ribosome stalling can lead to altered folding pathways and distinct Minima. J Mol Biol. 2008;383(2):281-91.

33. Krashia P, Moroni M, Broadbent S, Hofmann G, Kracun S, Beato M, et al. Human alpha 3 beta 4 neuronal nicotinic receptors show different stoichiometry if they are expressed in xenopus oocytes or Mammalian HEK293 cells. Plos One. 2010;5(10):e13611.

34. d'Incamps BL, Ascher P. High affinity and low affinity heteromeric nicotinic acetylcholine receptors at central synapses. J Physiol Lond. 2014;592(19):4131-6.

35. Bartoszewski RA, Jablonsky M, Bartoszewska S, Stevenson L, Dai Q, Kappes J, et al. a synonymous single nucleotide polymorphism in delta F508 cftr alters the secondary structure of the mRNA and the expression of the mutant protein. J Biol Chem. 2010;285(37):28741-8.

36. Lavner $Y$, Kotlar D. Codon bias as a factor in regulating expression via translation rate in the human genome. Gene. 2005;345(1):127-38.

37. Dittmar KA, Goodenbour JM, Pan T. Tissue-specific differences in human transfer RNA expression. Plos Genet. 2006;2(12):2107-15.

38. Novoa EM, de Pouplana LR. Speeding with control: codon usage, tRNAs, and ribosomes. Trends Genet. 2012;28(11):574-81.

39. Lavner $Y$, Kotlar D. Codon bias as a factor in regulating expression via translation rate in the human genome. Gene. 2005;345(1):127-38.

40. Giglione C, Fieulaine S, Meinnel T. Cotranslational processing mechanisms: towards a dynamic 3D model. Trends Biochem Sci. 2009;34(8):417-26.

41. Jacobo SMP, DeAngelis MM, Kim IK, Kazlauskas A. Age-related macular degeneration-associated silent polymorphisms in HtrA1 impair its ability to antagonize insulin-like growth factor 1. Mol Cell Biol. 2013;33(10):1976-90.

42. Gruber AR, Lorenz R, Bernhart SH, Neuboock R, Hofacker IL. The Vienna RNA websuite. Nucleic Acids Res. 2008;36:W70-4.

\section{Submit your next manuscript to BioMed Central and take full advantage of:}

- Convenient online submission

- Thorough peer review

- No space constraints or color figure charges

- Immediate publication on acceptance

- Inclusion in PubMed, CAS, Scopus and Google Scholar

- Research which is freely available for redistribution 